\title{
Comparison of two methods in the treatment of congenital pseudarthrosis of clavicle: multicenter experience
}

\author{
Jin $\mathrm{Li}^{1 \dagger}$, Sheng Ping Tang ${ }^{2 \dagger}$, Hai Bo $\mathrm{Mei}^{3 \dagger}$, Jing Fan Shao ${ }^{4 \dagger}$, Bao Jie Shi ${ }^{5+}$, Hai Qiang Wang ${ }^{6}$, Xin Tang ${ }^{1 *}$ (D) and
} Chinese Multi-center Pediatric Orthopedic Study Group (CMPOS)

\begin{abstract}
Background: Congenital pseudoarthrosis of the clavicle (CPC) is an uncommon entity. Owing to its scarce presentation, treatment of this disorder has not been well established. This study aimed (1) to compare surgical treatment methods that included excision of pseudoarthrosis and iliac crest bone graft and fixate with either the elastic stable intramedullary nail (ESIN) or K-wires or plate and screws, and (2) to assess the clinical outcomes of two different surgical methods.

Methods: A multi-central retrospective study was performed between 2013 and 2017 in four tertiary teaching hospitals. Fifteen clavicles of 11 children were identified as CPC. All patients underwent pseudarthrosis resection and iliac crest bone autograft. They were divided into two groups as per the surgical treatment they underwentplate stabilization as group A and elastic stable intramedullary nailing (ESIN) or K-wires as group B. Nine clavicles in 6 patients in group A and 6 clavicles in 5 patients in group B, were included. The Quick Disabilities of the Arm and Shoulder (QuickDASH) score was used to assess patients' satisfaction and function following treatment at each follow-up.
\end{abstract}

Results: There were eight boys and three girls, with an average age of 4.7 years. All patients, except one with intellectual impairments, had radiological healing. Implant removal time was significantly shorter in group B compared to group A. No statistically significant differences existed in terms of age at surgery, time of radiological healing, complication, and clinical outcome between different groups.

Conclusion: Surgical resection of pseudoarthrosis with an iliac crest bone graft was an effective means of surgical treatment in CPC. However, ESIN or K-wires can achieve shorter union time compared to the plate. Hence, surgical treatment is recommended for congenital pseudarthrosis of clavicular in pediatric patients.

Level of evidence: Retrospective comparative study; Level III

Keywords: Congenital pseudarthrosis of clavicular, Surgical management, lliac crest bone grafting, Elastic stable intramedullary nailing, K-wires, Plate

\footnotetext{
* Correspondence: dr xintang@hust.edu.cn

†Jin Li, Sheng Ping Tang, Hai Bo Mei, Jing Fan Shao and Bao Jie Shi contributed equally to this work.

'Department of Orthopedics, Union Hospital, Tongji Medical College, Huazhong University of Science and Technology, Wuhan 430022, China Full list of author information is available at the end of the article
}

(c) The Author(s). 2021 Open Access This article is licensed under a Creative Commons Attribution 4.0 International License, which permits use, sharing, adaptation, distribution and reproduction in any medium or format, as long as you give appropriate credit to the original author(s) and the source, provide a link to the Creative Commons licence, and indicate if changes were made. The images or other third party material in this article are included in the article's Creative Commons licence, unless indicated otherwise in a credit line to the material. If material is not included in the article's Creative Commons licence and your intended use is not permitted by statutory regulation or exceeds the permitted use, you will need to obtain permission directly from the copyright holder. To view a copy of this licence, visit http://creativecommons.org/licenses/by/4.0/ The Creative Commons Public Domain Dedication waiver (http://creativecommons.org/publicdomain/zero/1.0/) applies to the data made available in this article, unless otherwise stated in a credit line to the data. 


\section{Introduction}

Congenital pseudarthrosis of clavicular (CPC) is a rare disease, which was first reported in 1910 by Fitzwilliams. It has a predilection for the right clavicle in girls $[1,2]$, seldom occurred in the left side. Bilateral CPC occurs only in up to $10 \%$ of the cases according the literature $[3,4]$.

The etiology of CPC remains unclear; it is believed to be associated with the failure to fuse ossification centers of clavicle during the embryogenetic stage [5]. Another plausible hypothesis is related to the subclavian artery on the developing clavicle, which situates at a higher position than the normal during intrauterine life $[3,6]$. Clinically, CPC usually presents a painless protuberance in the middle of the clavicle after birth or later in childhood. The deformity tends to be more evident with growth or some activities [4]. Surgical intervention is now widely accepted for the treatment of CPC. However, there is an obvious gap between basic and clinical research of CPC. This gap needs to be filled by emerging method and process such as translational orthopedics [7].

This multi-central retrospective study aimed to assess the clinical outcomes of different surgical methods in the treatment of CPC. This work may accelerate understanding more congenital pseudoarthrosis of the clavicle.

\section{Materials and methods}

From 2013 January to 2017 December, all the cases of $\mathrm{CPC}$ who underwent surgical treatment were retrospectively reviewed at four high-volume, geographically separated, pediatric orthopedic centers. The inclusion criteria of the study were (1) pediatric patients aged $<14$ years with a diagnosis of CPC, (2) undergoing surgical procedures and the iliac crest bone graft, (3) with a minimal follow-up of at least 24 months. Exclusion criteria were (1) follow-up less than 24 months, (2) suffer from cranial dysostosis, neurofibromatosis or other pathologic pseudarthroses of clavicular, (3) post-traumatic pseudarthrosis, and (4) incomplete medical records. The Ethics Committee of authors' hospital approved the study. All guardians of these patients signed written informed consent.

All patients in the cohort underwent surgical treatment, including excision of the pseudarthrosis followed with implantation of iliac crest bone graft and stabilization with either ESIN or K-wires, or plates and screws. Details of surgical procedures were explained to the patient guardians and also explained the types of implants and let them choose. So, patients were divided into two groups as per the surgical treatment they underwent-plate stabilization as group A and elastic stable intramedullary nailing (ESIN) or K-wires as group B. Nine clavicles in 6 patients in group A and 6 clavicles in 5 patients in group B, were included. Postoperatively, all patients were advised to use a sling for 4-6 weeks. Implants were removed following radiological union or if unexpected complications occurred, such as deep infection or implants migration.

Hospital medical records and follow-up radiographs of each CPC patient were the main resources, including age at surgery, time to radiographic osseous consolidation, further surgery, implant removal time, and complications. Radiographic evaluation was taken at 4- or 6week intervals before radiographic union, then change to 6- to 12-month intervals after implant removal. We used the Quick Disabilities of the Arm and Shoulder (QuickDASH) score to assess patients' satisfaction and function after implant removal at final follow-up.

\section{Statistical analysis}

Statistical analyses were performed using SPSS19.0 software (SPSS, IL, USA). Quantitative variables were expressed as mean \pm standard deviation. Categorical variables were presented as values (percentages). A $p$ value of $<0.05$ is regarded as statistically significant at $95 \%$ confidence interval.

\section{Results}

In total, 3 girls and 8 boys with 15 clavicles diagnosed as $\mathrm{CPC}$ were recruited. All patients had a painless lump without other subjective anomalies or disfunction, and all of them underwent the same surgical procedure using either ESIN or K-wires or plates and screws. The demographic and clinical data of the patients are illustrated in Tables 1 and 2.

In group A, 3 patients were males and 3 patients were females with a mean age at the time of surgery of 4.7 years. All the plates were locking plate. There were 3 patients with bilateral involvements, one was operated at the same time but the other two were 4- or 6-month intervals, whereas left side was in 1 and right side was in 2 patients. The mean follow-up period was 3 years. All patients achieved both clinical and radiological union at a median duration of $4.00 \pm 0.63$ months (range, 3-5 months). The average duration of implant removal was $11.33 \pm 1.97$ months postoperatively. The treatment and union process of a typical case shown in Fig. 1. All patients were satisfied with improved functional outcomes.

In group B, all 5 patients were males with a mean age at the time of surgery of 5.2 years. Only one patient was bilateral involvement, got operation at the same time, the other 4 patients were on the right side. The mean follow-up period was 3.5 years. Out of 5 patient, 4 patients with unilateral involvement achieved clinical and radiological union at a median duration of $3.75 \pm 1.50$ months (range, 3-6 months). The average duration of implant removal for these patients was $4.60 \pm 1.51$ months postoperatively. 
Table 1 Demographic and data of patients in case series

\begin{tabular}{|c|c|c|c|c|c|c|c|}
\hline & Sex & Side & $\begin{array}{l}\text { Age at surgery } \\
\text { (months/side) }\end{array}$ & $\begin{array}{l}\text { Fixation (ESIN, } \\
\text { K-wire, plate) }\end{array}$ & $\begin{array}{l}\text { Radiological healing } \\
\text { (months postoperative) }\end{array}$ & $\begin{array}{l}\text { Removal of material } \\
\text { (months postoperative) }\end{array}$ & $\begin{array}{l}\text { Complication } \\
\text { (yes }=0, \text { no=1) }\end{array}$ \\
\hline \multirow[t]{2}{*}{1} & $M$ & B & 141 & ESIN & & $3(L)$ & 0 \\
\hline & & & 141 & ESIN & & $6(\mathrm{R})$ & 0 \\
\hline 2 & $M$ & R & 44 & ESIN & 3 & 5 & 1 \\
\hline 3 & $M$ & $\mathrm{R}$ & 23 & ESIN & 3 & 3 & 1 \\
\hline \multirow[t]{2}{*}{4} & $F$ & B & $78(\mathrm{~L})$ & Plate & 4 & 13 & 1 \\
\hline & & & $84(\mathrm{R})$ & Plate & 4 & 7 & 1 \\
\hline 5 & $M$ & $R$ & 66 & K-wire & 3 & 4 & 1 \\
\hline 6 & $\mathrm{~F}$ & $R$ & 41 & Plate & 3 & 10 & 1 \\
\hline 7 & $\mathrm{~F}$ & $L$ & 59 & Plate & 4 & 14 & 1 \\
\hline 8 & $M$ & R & 38 & K-wire & 6 & 6 & 1 \\
\hline \multirow[t]{2}{*}{9} & M & B & $45(R)$ & Plate & $4(R)$ & $12(\mathrm{R})$ & 1 \\
\hline & & & $49(\mathrm{~L})$ & Plate & $5(\mathrm{~L})$ & $8(L)$ & 1 \\
\hline \multirow[t]{2}{*}{10} & $M$ & B & $91(\mathrm{R})$ & Plate & 5 & 10 & 1 \\
\hline & & & $91(\mathrm{~L})$ & Plate & 5 & 10 & 1 \\
\hline 11 & M & $\mathrm{R}$ & 36 & Plate & 4 & 9 & 1 \\
\hline
\end{tabular}

$M$ male, $F$ female, $L$ left, $R$ right, $B$ bilateral

However, the patient who had bilateral involvement failed to unite. The failure of union might attribute to postoperative complication, for the reason that he was lacking of treatment care for his intellectual impairments. He pulled out the left-sided pin at 3 months following surgery by himself and the right-sided pin was also migrated from the original site at 6 months followup. The pin was then removed, considering the risk of piercing the mediastinum, and the pseudarthrosis failed to heal. The treatment and union process of a typical case shown in Fig. 2. All patients, except 1 with bilateral involvement, were satisfied with improved functional outcomes.

Implant removal time was significantly shorter in group B compared to group A $(p<0.001)$ (Table 2$)$. No statistically significant differences existed in terms of age at surgery, time of radiological healing, complication, and clinical outcome. The QuickDASH score was 0 for all patients except the one whose pseudarthrosis failed to heal in group B.

\section{Discussion}

Most important finding of the study is that both the surgical procedure provides satisfactory clinical and functional outcomes. However, patient selection is crucial as one of the patients with intellectual impairment in group $B$ failed to unite postoperatively.

Congenital pseudarthrosis of the clavicle is an uncommon condition for which only over 200 cases have been reported $[3,8]$. The malformation is more seen in females, mainly exists on the right side. Interestingly, both the genders were equally involved in this study, having more bilateral involvement cases (36\%). The small sample size may have been responsible for this surprising result, and Persiani P. et al. also found no statistically significant difference between the girls and boys [9].

There were two opinions in the treatment of the CPC. The one is CPC should be treated conservatively. The other is surgical treatment was better for CPC. Considering the fact that the congenital pseudarthrosis of the clavicle causes only a few symptoms [10], a group of the authors preferred a conservative treatment [11, 12]. While surgical treatment is now progressively accepted due to increasingly obvious cosmetic deformity, pain, and functional disorders with growth $[2,3,8]$. Some authors considered the operative indication in a combination of cosmetic appearance and functional impairment. Pain and neurovascular symptoms such as thoracic outlet syndrome (TOS) also should be included [13]. Internal fixation was thought not necessary in children

Table 2 Summary of patients' demographic and clinical characteristics

\begin{tabular}{llll}
\hline & Plate & ESIN or K-wires & $P$ value \\
\hline Age at surgery (months) & $62.40 \pm 46.58$ & $58.33 \pm 22.05$ & 0.853 \\
Radiological healing (months postoperative) & $3.75 \pm 1.50$ & $4.00 \pm 0.63$ & 0.721 \\
Removal of material (months postoperative) & $4.60 \pm 1.51$ & $11.33 \pm 1.97$ & $\mathbf{0 . 0 0 0}$ \\
\hline
\end{tabular}



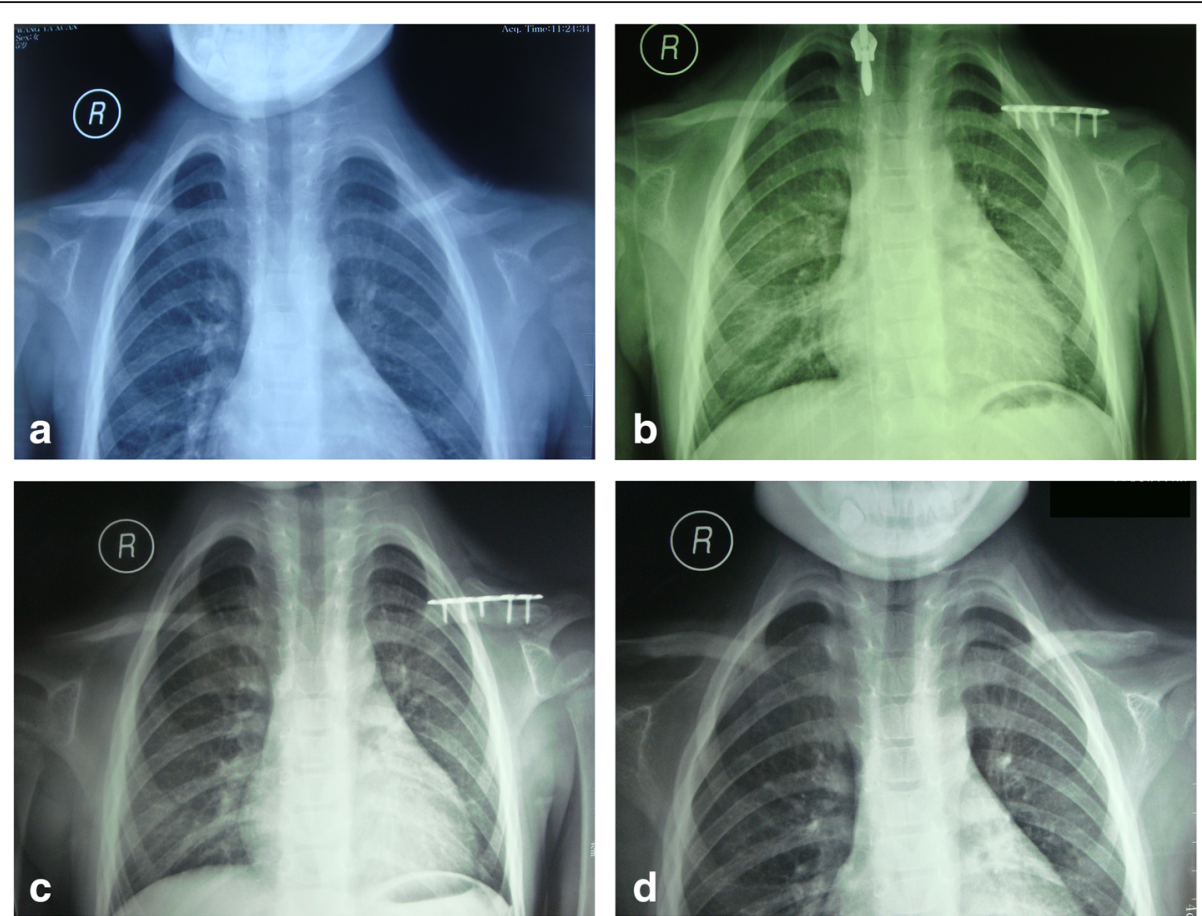

Fig. 1 a Radiographic presentation of a 4.9-year-old girl with left clavicular pseudarthrosis preoperatively. b Postoperative radiograph with pseudarthrosis resection and iliac crest bone autograft stabilized with plate. c 11 months postoperative follow-up. $\mathbf{d} 8$ months after removing the plate
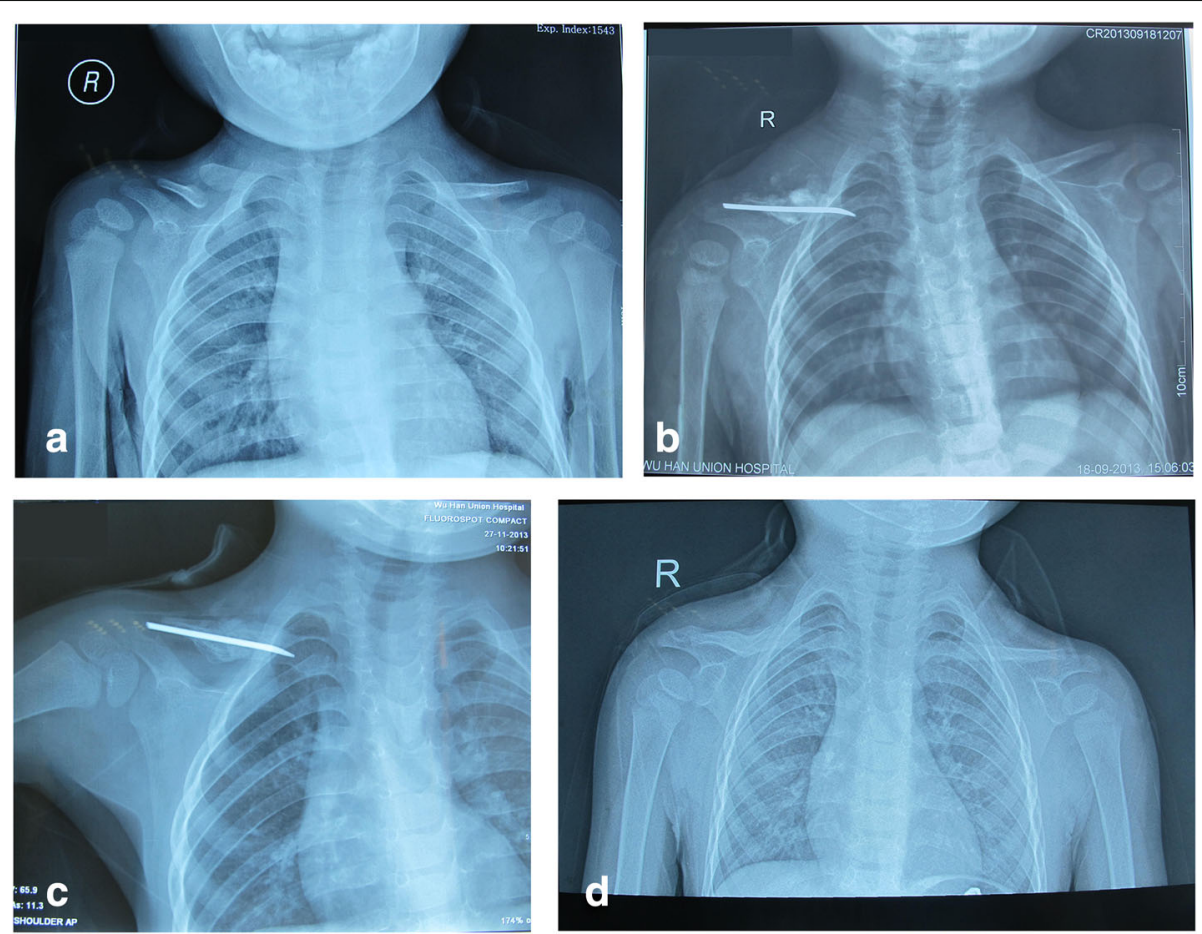

Fig. 2 a Radiographic presentation of a 2-year-old boy with right-sided CPC preoperatively. b Postoperative radiograph with pseudarthrosis resection and iliac crest bone autograft stabilized with ESIN. c 2 months postoperative. $\mathbf{d} 6$ months after removing the ESIN 
aged $<3$ years [14]. In this study, all the children and their parents asked for iliac crest bone graft and internal fixation in order to avoid increasingly obvious cosmetic deformity and unfavorable effect possibly.

All the cases in this study got autologous bone graft in operations. The use of bone graft has been strictly recommended in the literature, which leads to a higher percentage of success in union [15]. Meanwhile, using the autologous bone graft is preferable over allograft as of more beneficial biological characteristics. Iliac crest graft is the classic autologous bone graft. There were no successful reports of autologous bone graft substitution. Elliot et al. used a bovine cancellous xenograft to substitute iliac crest bone; however, it failed [8]. Another case of incorporating bone graft substitute leads to nonunion and a large defect [16]. According to the result of this study, autologous bone graft shows a higher percentage of the successful union, which was consistent with the literature.

The attitude toward surgical techniques is controversial. Di Gennaro GL et al. preferred the K-wire fixation when encountering septic nonunion using a plate fixation [17], but Toledo et al. reported an unstable smooth pin possibly result in a severe brachial plexus injury [11]. One study analyzes the treatment result of CPC by plate or K-wire and recommends internal fixation with Kirschner wires [9], whereas Chandran et al. reported that plate provides early union and with fewer complications compared to pin fixation (100\% vs $60 \%)$ [18]. The stability may be one of the key points of bone union and avoiding complications. However, plate, ESIN, or K-wire did not show advantage of stability in this multi-central retrospective study. One patient in group B with bilateral involvement failed to unite. The reason for failure was because of wrong patient selection. As this male patient was suffering from intellectual impairment, and he pulled out the left pin at 3 months following surgery and the right pin was also migrated from the original site at 6 months follow-up. The pin was then removed, considering the risk of piercing the mediastinum, and the pseudarthrosis failed to heal. The failure could be prevented by the use of more rigid fixation like plate and screws in this patient. Another reason of failure was the age at operation. Some experts considered the best age was between 4 and 5 years [17-19]. If the age at operation was far beyond the best age, the difficulty of union will increase because the gap between bone graft and clavicle may need more time to heal. Indeed, the younger the child, the lesser symptoms may be present and more probability of splintering the bone. Surgeons should pay attention to the possibility of pin migration, which may be dangerous to the cardiovascular system. In addition to avoiding the ESIN or K-wires method, we also advise an early surgical age of CPC according with other authors.
Upper extremity function of most patients except one case stabilized with ESIN was normalized according to the QuickDASH score in this study. They all had a satisfactory prognosis accompanying with full range of painfree movement at the shoulder and unrestricted activities and had no complications such as nonunion and infection. Implant removal for ESIN or K-wires group was significantly shorter than the plate group. This result was consistent with Lorente Molto and Currarino Guido's study that it took much longer to remove plate (6 to 12 months) than pin (8 to 10 weeks) $[4,20]$.

Because of the rarity of the disease, this study was limited by small sample size. A large number of cases could have resulted in different results especially in patients' demographics, surgical outcomes, and complications. Although all the patients achieved clinical and radiographic union, follow-up durations still varied. Lacking of randomization is another limitation of this study. As a retrospective multiple-center study with the patient guardians-chosen treatment, there were confounding factors even within same surgical treatments. Further studies with more patients and long-term follow-up are necessary.

\section{Conclusion}

ESIN or K-wires seems to achieve quicker union compared to stabilization with plate in the treatment of CPC. K-wires should not be recommended considering the risk of migration into the medial structures, including the thoracic cavity and the great subclavian and other vessels. Surgical resection of pseudoarthrosis with an iliac crest bone graft and stabilization with plate was an effective means of surgical treatment in CPC, but need further research with more patients and long-term follow-up.

\section{Abbreviations}

CPC: Congenital pseudarthrosis of the clavicle; ESIN: Elastic stable intramedullary nailing; K-wires: Kirschner wires; QuickDASH: Quick Disabilities of the Arm and Shoulder; TOS: Thoracic outlet syndrome

\section{Acknowledgements}

Chinese Multi-center Pediatric Orthopedic Study group (CMPOS) positively assisted us in cases collection. ZiLong Huang, Jin Tang, and JinPeng He were involved in data collection and cases follow-up.

\section{Authors' contributions}

J.L., SP. T., HB.M., JF.S., and BJ.S. drafted the manuscript, performed data collection, and cases follow-up. X.T., HQ.W, and S.R. finalized the manuscript. X.T. and J.L. were responsible for literature search and study design. The manuscript has been read and approved by all authors; each author believes that the manuscript represents honest work. The authors read and approved the final manuscript.

\section{Funding}

This study was supported by the National Natural Science Foundation of China in data collection and cases follow-up (NNSFC grant 81470100 and 81572182). 


\section{Availability of data and materials}

The datasets used and/or analyzed during the current study are available from the corresponding author on reasonable request.

\section{Declarations}

\section{Ethics approval and consent to participate}

The Ethics Committee of Tongji Medical College, Huazhong University of Science and Technology (IORG No: IORG0003571) gave a final approval for this study.

All guardians of patients signed written informed consent to participate.

\section{Consent for publication}

All guardians of patients signed written informed consent for publication.

\section{Competing interests}

The authors have no conflict of interest relevant to this article.

\section{Author details}

${ }^{1}$ Department of Orthopedics, Union Hospital, Tongji Medical College, Huazhong University of Science and Technology, Wuhan 430022, China. ${ }^{2}$ Department of Pediatric Orthopedics, Shenzhen Children's Hospital, Shenzhen 518046, China. ${ }^{3}$ Department of Orthopedics, Hunan Children's Hospital, Changsha 410007, China. ${ }^{4}$ Department of Pediatric Surgery, Tongji Hospital, Tongji Medical College, Huazhong University of Science and Technology, Wuhan 430030, China. ${ }^{5}$ Department of General Surgery, Xiang'an Hospital of Xiamen University, Xiamen 361000, China. Institute of Integrative Medicine, Shaanxi University of Chinese Medicine, Xixian Avenue, Xi'an 712046, Xixian District, China.

Received: 11 December 2020 Accepted: 20 April 2021

Published online: 08 May 2021

\section{References}

1. Beslikas TA, Dadoukis DJ, Gigis IP, Nenopoulos SP, Christoforides JE. Congenital pseudarthrosis of the clavicle: a case report. J Orthop Surg. 2007; 15(1):87-90. https://doi.org/10.1177/230949900701500120.

2. Galanopoulos I, Ashwood N, Garlapati AK, Fogg Q, (2012) Congenital pseudarthrosis of clavicle: illustrated operative technique and histological findings. BMJ Case Rep, 2012. DOI: https://doi.org/10.1136/bcr-2012-006908, sep20 1, bcr2012006908.

3. De Figueiredo MJ, Dos Reis BS, Akkari M, Prado JC, Santili C. Congenital pseudarthrosis of the clavicle. Rev Bras Ortop. 2015;47(1):21-6. https://doi. org/10.1016/S2255-4971(15)30341-4.

4. Currarino G, Herring JA. Congenital pseudarthrosis of the clavicle. Pediatr Radiol. 2009;39(12):1343-9. https://doi.org/10.1007/s00247-009-1396-1.

5. Gibson DA, Carroll N. Congenital pseudarthrosis of the clavicle. J Bone Joint Surg Br. 1970;52(4):629-43.

6. Sung TH, Man EM, Chan AT, Lee WK. Congenital pseudarthrosis of the clavicle: a rare and challenging diagnosis. Hong Kong Med J. 2013;19(3): 265-7. https://doi.org/10.12809/hkmj133648.

7. Mediouni M, Schlatterer DR, Madry H, Cucchiarini M, Rai B. A review of translational medicine. The future paradigm: how can we connect the orthopaedic dots better? Curr Med Res Opin. 2018;27:1-26.

8. Abdellaoui H, Atarraf K, Chater L. Afifi MA, (2017) Congenital pseudarthrosis of the clavicle treated by Masquelet technique. BMJ Case Rep. 2017. https:// doi.org/10.1136/bcr-2017-221557.

9. Persiani P, Molayem I, Villani C, Cadilhac C, Glorion C. Surgical treatment of congenital pseudarthrosis of the clavicle: a report on 17 cases. Acta Orthop Belgica. 2008;74(2):161-6.

10. Beals RK, Sauser DD. Nontraumatic disorders of the clavicle. J Am Acad Orthop Surg. 2006;14(4):205-14. https://doi.org/10.5435/00124635-200604 000-00002.

11. Toledo LC, MacEwen GD. Severe complication of surgical treatment of congenital pseudarthrosis of the clavicle. Clin Orthop Related Res. 1979;139: 64-7.

12. Kuhnle G, Collins RA, Scott JE, Keil GM. Bovine interleukins 2 and 4 expressed in recombinant bovine herpesvirus 1 are biologically active secreted glycoproteins. J Gen Virol. 1996;77(Pt 9):2231-40. https://doi.org/1 0.1099/0022-1317-77-9-2231.
13. Shalom A, Khermosh O, Wientroub S. The natural history of congenital pseudarthrosis of the clavicle. J Bone Joint Surg Br. 1994;76(5):846-7.

14. Kim AE, Vuillermin CB, Bae DS, Samora JB, Waters PM, Bauer AS. Congenital pseudarthrosis of the clavicle: surgical decision making and outcomes. J Shoulder Elbow Surg. 2020;29(2):302-7. https://doi.org/10.1 016/j.jse.2019.06.002.

15. Cadilhac C, Fenoll B, Peretti A, Padovani JP, Pouliquen JC, Rigault P. Congenital pseudarthrosis of the clavicle: 25 childhood cases. Rev Chirurgie Orthop Reparatrice l'appareil Moteur. 2000;86(6):575-80.

16. Glotzbecker MP, Shin EK, Chen NC, Labow BI, Waters PM. Salvage reconstruction of congenital pseudarthrosis of the clavicle with vascularized fibular graft after failed operative treatment: a case report. J Pediatr Orthop. 2009;29(4):411-5. https://doi.org/10.1097/BPO.0b013e3181a5ebff.

17. Di Gennaro GL, Cravino M, Martinelli A, et al. Congenital pseudarthrosis of the clavicle: a report on 27 cases. J Shoulder Elbow Surg. 2017;26(3):e65-70. https://doi.org/10.1016/j.jse.2016.09.020.

18. Chandran P, George H, James LA. Congenital clavicular pseudarthrosis: comparison of two treatment methods. J Children's Orthop. 2011;5:1-4. https://doi.org/10.1007/s11832-010-0313-3.

19. Owen R. Congenital pseudarthrosis of the clavicle. J Bone Joint Surg Br. 1970;52(4):644-52.

20. Lorente Molto FJ, Bonete Lluch DJ, Garrido IM. Congenital pseudarthrosis of the clavicle: a proposal for early surgical treatment. J Pediatr Orthop. 2001; 21(5):689-93. https://doi.org/10.1097/01241398-200109000-00026.

\section{Publisher's Note}

Springer Nature remains neutral with regard to jurisdictional claims in published maps and institutional affiliations.
Ready to submit your research? Choose BMC and benefit from:

- fast, convenient online submission

- thorough peer review by experienced researchers in your field

- rapid publication on acceptance

- support for research data, including large and complex data types

- gold Open Access which fosters wider collaboration and increased citations

- maximum visibility for your research: over $100 \mathrm{M}$ website views per year

At BMC, research is always in progress.

Learn more biomedcentral.com/submissions 